\title{
Building a System for the Hospital's Emergency Departments Based on the Queuing Theory
}

\author{
${ }^{1}$ Mohammed Awad Mohammed AtaElfadiel, ${ }^{2}$ Eiman Alsiddig Altayeb Ibrahim, \\ ${ }^{3}$ Sara Abdullah Saud Al-Owaidh, ${ }^{4}$ Haya Khalid Fadhel Al-Aqeel, ${ }^{5}$ Asaiyl Saud Yahya Al-Oudah \\ ${ }^{1}$ Assistant Professor, Faculty of Computer Science, Open University of the Sudan, Sudan \\ ${ }^{1}$ Assistant Professor, Department of Computer Science and Information, College of Sharia and Islamic Studies at Al-Ahsa, Imam \\ Muhammad bin Saud Islamic University, Saudi Arabia \\ ${ }^{2}$ Assistant Professor, College of Computer Science and Information Technology, Omdurman Islamic university, Sudan \\ 3,4,5 Department of Computer Science and Information, College of Sharia and Islamic Studies at Al-Ahsa, Imam Muhammad bin \\ Saud Islamic University, Saudi Arabia
}

\begin{abstract}
Reducing the waiting time in the emergency departments is one of the most important factors that saving lives depends on, which means every minute we have is saving someone else life. In a traditional system, doctors and the other health care staffs waste about 15 to 25 min's on average to check the patient information which is considered too much time in such cases. The proposed system handle this problem by designing a queuing model, that takes the patient's initial information within no more than five minutes, and then classifies his health situation, using the Canadian's system which is determined health case using one of the different five colors (grey: Non-Urgency, green: Less Urgency, yellow: Urgency, red: Emergency, blue: Resuscitation case); Thus, the medical staff can deal with the cases in the proper order. Also, the proposed system records the patient's arrival time (AT), so that the ordering in the queue done correctly in case of more than one patient is classified in the same medical case. Eventually, the researchers implemented the system as a desktop application using Python programming language to design the main interfaces, and SQL to design the databases.
\end{abstract}

Keywords: Queuing theory; Queuing model; Queuing systems; Emergency room; Emergency department; Medical systems; Hospital management; waiting time.

\section{INTRODUCTION}

Patient expect a good and fast treatment, even when he has a simple or case. What are medical staffs should do at emergency department? What are their missions? And their role in providing service and how are patients treated? What are the cases that need fast treatment? And how are these cases get sorted?
Hospitals face the issue of cases queuing for their patients in the emergency department, which lead them to lose the efficiency of their service.

In this model the researcher classified cases into categories depending on patient health situation. And, when there are many patients in the same level, deal with them according to their arriving time. Considering that the waiting time is one of the most important factors determining the quality of health services provided.

Often, the emergency department is so crowded in any hospital, which needs to rearrange all time. So, this designed system aimed to provide an electronic, auto updated case panel showing patients information in different colors. The emergency department needs to manage the information which is going to be displayed on the screen to help to improve services.

The system will have a significant impact, as it is compatible with the Canadian system [1] which is used by the ministry of health in the Saudi Arabia kingdom hospitals. On the other side, other hospitals outside can customize it according to their needs.

The system will arrange all patient details, and makes it reachable to the staff, so doctors can treat more patients and there will be no long queue, which is good for both.

The system will show patient information on a large screen, so the medical staff working at the emergency department can see it, (what is patient initially diagnose, And who will see a doctor next).

\section{RELATED WORK}

As in [2], system designed for emergency centers in New Zealand, and it depends on direct video communication between the patients and emergency department staff, before 
ISSN (online): 2581-3048

Volume 4, Issue 6, pp 52-59, June-2020

https://doi.org/10.47001/IRJIET/2020.406007

they directed to the hospital, and before they reach the staff will classify the case. This application reduces waiting time for patients by sorting cases and directing them remotely before reaching the emergency center; eliminating number of patients who do not need an emergency service, make the staff can focus on emergency cases. On the other hand, the application is designed to work in New Zealand hospitals, it is a custom application, and therefore needs to redesigned in case of deploy it outside New Zealand, while the proposed system depends on the Canadian which can be applied everywhere. Furthermore [2] classified patients into only two categories emergency and non-emergency, while the proposed system classified patients into 5 categories based on the Canadian system.

In [3] the main function of the system is locating medical centers near the patient geographically through GPS, calculating the arrival time. Also, it Links the NHS medical site to record information (expected waiting time or destiny and the quality of the injury and the degree of classification), which reduces the time allocated for treatment as well as reduced the arrival time, waiting time, sorting time and classification. Finally it records the symptoms and complaint of the patient before arrival.

But it is limited to the emergency facilities that developed for, while the proposed model is based on a general system that can be applied in any emergency department, effectively organizes queues based on the classification accuracy and the actual arrival time, thus reducing the expected waiting time for other cases.

In [4], the system uses a colorful screen (5 colors) numbered from 1 to 5 by Canadian classification of priority cases where the number 1 of the red bar means (Very Dangerous), 2 Orange (Unstable Critical), 3 Yellow (Stable Sickness), 4 Green (Very Stable), 5 Blue (Non-Emergency), Number of Waiters (patients in queue) and Waiting time for all Registered Cases.

The project reduces the waiting time by distracting the medical staff of the highest priority cases with appropriate waiting times for other cases. System lacks the ability of calculating the expected waiting time for each patient, while the proposed system added feature of recording the arrival time, so that it calculates the expected waiting time depending on case classification and the arrival time, even when there are several cases with the same classification reach the department in times close to each other.

All the previous solutions focused on arranging patients according to their health situation or their arrival time. In the proposed model, each case will be sorted according to both the arrival time and the medical situation of each.

\section{BACKGROUND}

Before we move on to building the model we must define some important terms, which include:

"A queuing theory is the mathematical study of the congestion and delays of waiting in line. Queuing theory examines every component of waiting in line to be served, including the arrival process, service process, number of servers, number of system places, and the number of customers - which might be people, data packets, cars, etc.’[5]

The emergency department, or accident and emergency department (ER), is a medical treatment department in hospitals for urgent cases that cannot wait for any role, where the emergency doctor is called and in turn he performs the necessary first aid such as stopping the bleeding if the patient is bleeding, then determines the specialist doctor who is called To remedy the situation. Most of the cases that come to the emergency department are from traffic accidents or ambulance cases.

The Canadian system is determined each case with a specific color:

- Non-Urgency: classified by grey and it's the case which we can let the patient wait for less than 120 mins, the color will turn to Purple if he will wait.

- Less Urgency: classified by green, he will wait less than 60 mins.

- Urgency: classified by yellow, he will wait less than 30 mins.

- Emergency: classified by red, he will wait less than 15 mins.

- Resuscitation: classified by blue, which means see patient immediately.

The Arrival time means the time the patient arrives at the hospital's emergency department, abbreviated by AT in this work.

\section{METHOD}

\section{a) Proposed Process}

Firstly, the data entry "better to be a nurse" should enter the patient information and determine the level of the medical situation after the initial examination "the database allows only authorized users". Secondly, the database accepts a number of requests include adding patient data, delete or modify it. The system display the patient's arrival time and other data that follows him, as well as his health situation represented in a specific color "according to the Canadian system". 


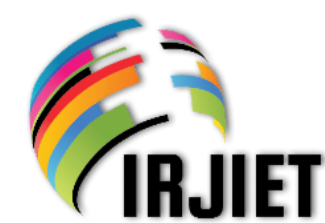

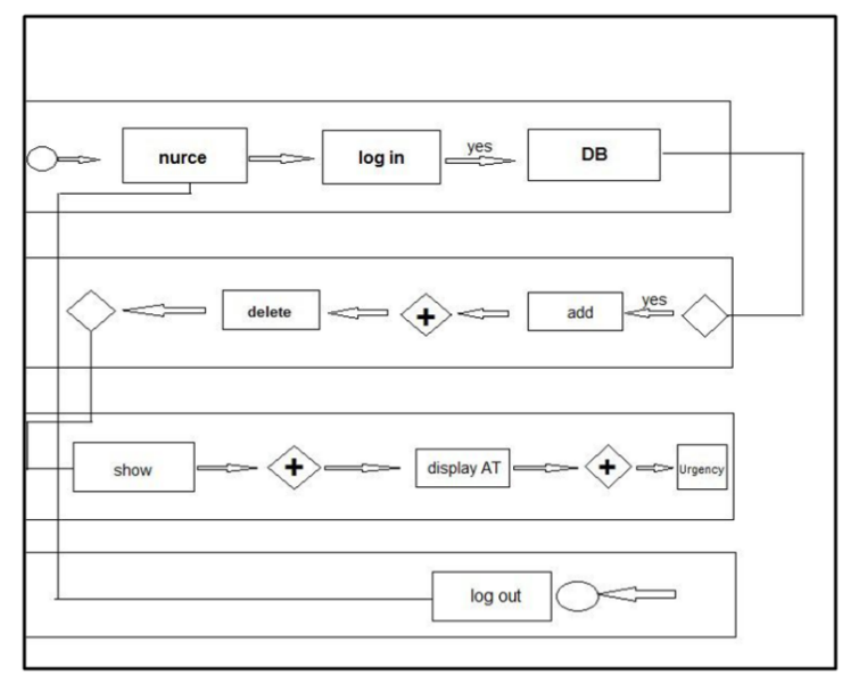

Figure 1: Proposed Business Process

b) Proposed system functional requirements

The proposed system includes the following requirements:

1. With regard to the emergency department, the main requirements to be store in the database is the basic information, such as Dept. no, Dept. name, capacity, number of medical staff... etc; allow update of theses information and search permissions with different criteria.

2. With regard to the Patient, the requirements are the ability to store patient's information including ID, name, gender, medical status and the arrival time.

3. With regard to the data entry user "probably nurse", the requirements should include login with valid user name and password, entering patient's information and update it.

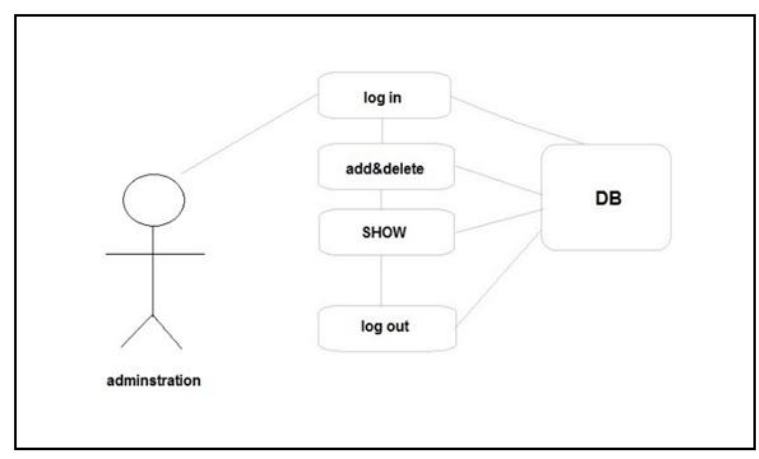

Figure 2: Use case for Functional Requirements

\section{c) System Modelling}

System modelling is the process of developing abstract models of a system, with each model presenting a different view or perspective of that system. It's about representing a system using some kind of graphical notation, which is now based on notations in the Unified Modeling Language UML [6].
ISSN (online): 2581-3048

Volume 4, Issue 6, pp 52-59, June-2020 https://doi.org/10.47001/IRJIET/2020.406007

\section{Activity diagrams}

The following activity diagram is drawn with all activities of the proposed system.

The Figure 3 shows the process of using the system, Starting with making a choice, whether the user has an account to $\log$ in or make a new one ( which can get the accessibility to login from the system administrator); so, the system have four choices:

1. Patient, which use to enter a new patient's information.

2. Show, which display the other patient's information with the colors.

3. Manage, which give a choice to delete any patient information from the system by entering his ID. no.

4. Logout, which allow user to sign out.

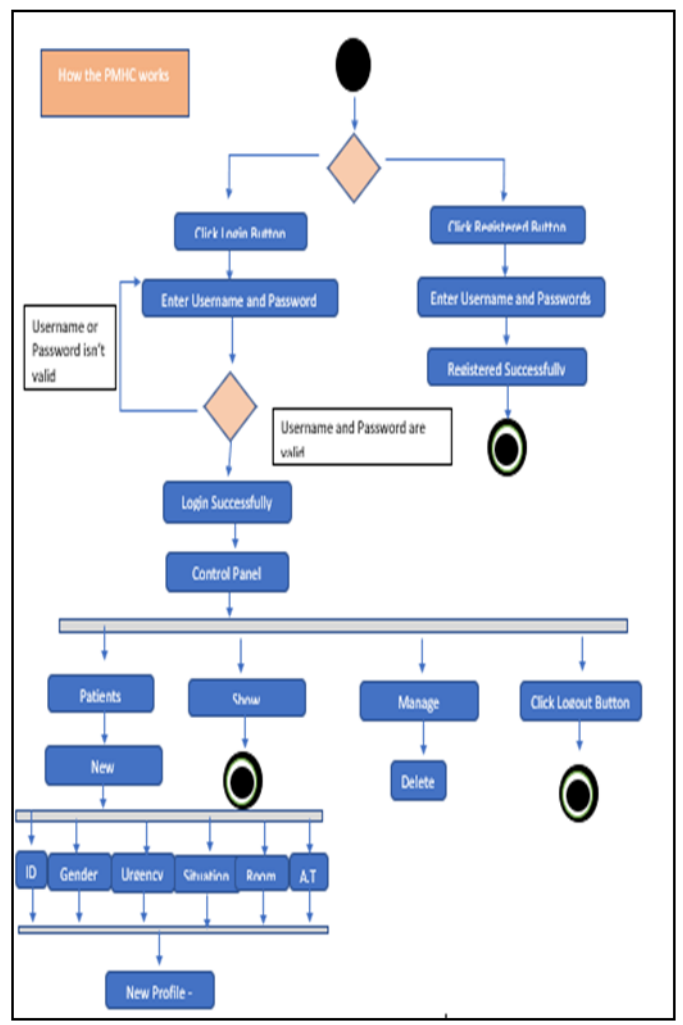

Figure 3: Activity Diagram

\section{Class Diagram}

The class diagram shows the objects, their properties, the operations of each object and the relations between these objects. The system consists of the following classes as shown in figure (4). 
/ (IRJ)

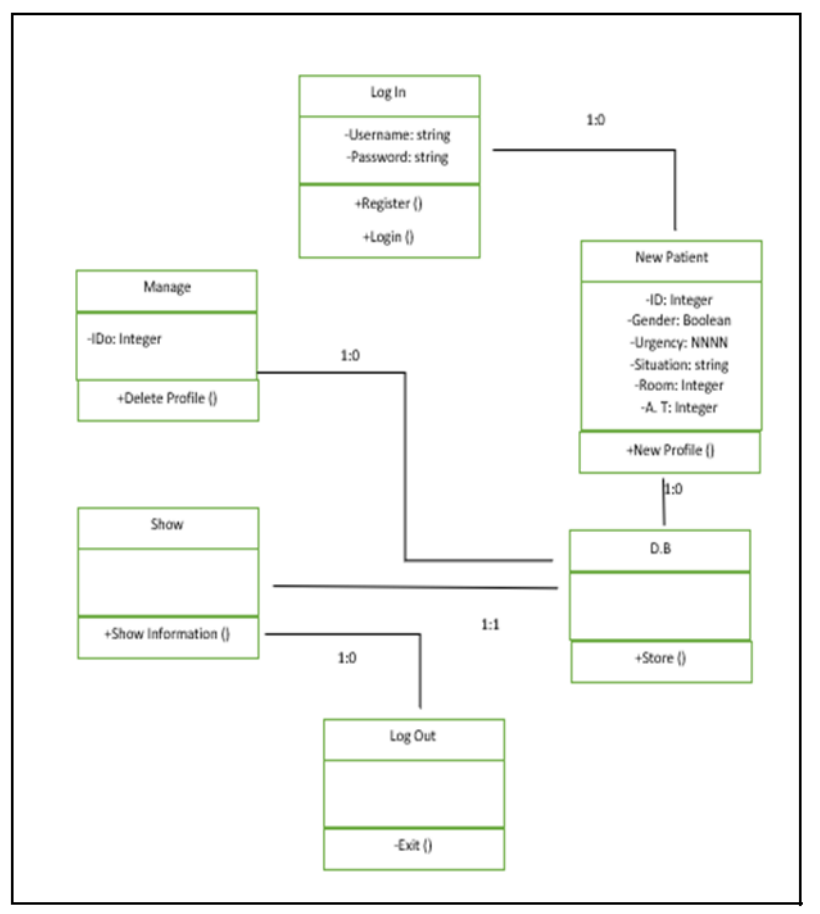

Figure 4: Class Diagram

\section{Sequence Diagrams}

The sequence diagram shows the order in which activities are carried out in chronological order.

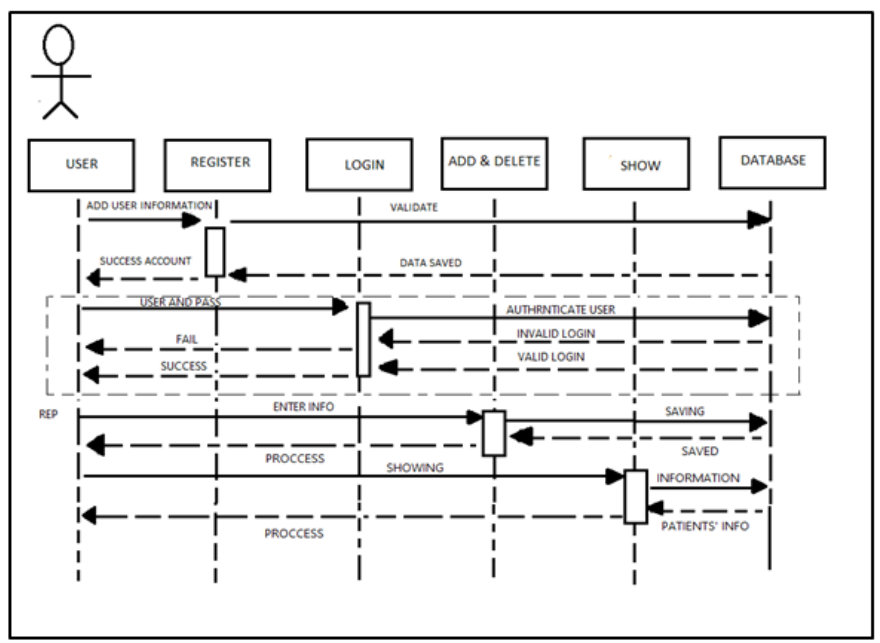

Figure 5: Sequence Diagram

As shown in figure 5 the sequence diagram shows the system functionalities, which are:

1. Log in, allow user to access system.

2. Add \& Delete, allow the user adding a new patient or to deleting is record by entering the ID. no.

3. D.B, where the data will be stored. Then can be able to manage the data by rolling back to the last step.

4. Show, display the patient's information with colors.

5. Logout, allow the user sign out of the system.
ISSN (online): 2581-3048

Volume 4, Issue 6, pp 52-59, June-2020 https://doi.org/10.47001/IRJIET/2020.406007

d) Data Modelling

\section{Entity Relationship diagram}

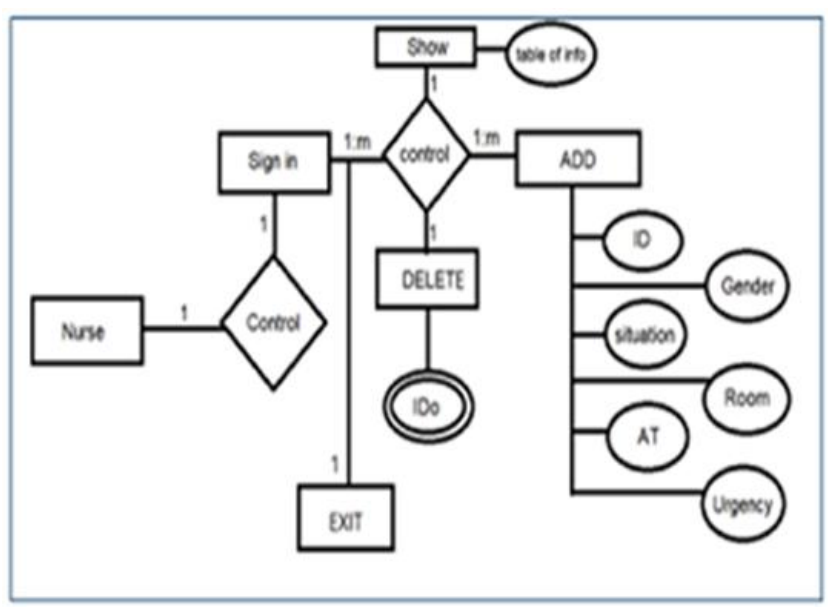

Figure 6: Entity Relationship Diagram

This figure shows the relationship between system entities.

\section{Data Dictionary}

As shown in table1, the researcher designed the data dictionary to build the system database.

\section{Component Diagram}

Figure 7 shows the component diagram which designed to help model implementation details and double-check that every aspect of the system's required functions is covered by planned development.

\begin{tabular}{|l|l|l|}
\multicolumn{2}{|c}{ Table 1: Data Dictionary } \\
\hline Data & Type & Description \\
\hline Username & String & The system user valid user name \\
\hline Password & String & The system user valid password \\
\hline ID & Integer & The identification numbers. \\
\hline Gender & String & Whether a Female or Male. \\
\hline Situation & String & The healthcare situation "diagnoses" \\
\hline Urgency & String & The Urgency color (high-low). \\
\hline Room & Integer & The room numbers. \\
\hline A. T & Integer & The Arrival Time. \\
\hline Add & String & Add a new patient's profile. \\
\hline Delete & Integer & Delete a patient's profile. \\
\hline Show & String & Show patient's information. \\
\hline New Profile & String & Make a new profile for a patient. \\
\hline D.B & String & Store the data inside it. \\
\hline IDo & Integer & Identification number for the database. \\
\hline & & \\
\hline
\end{tabular}




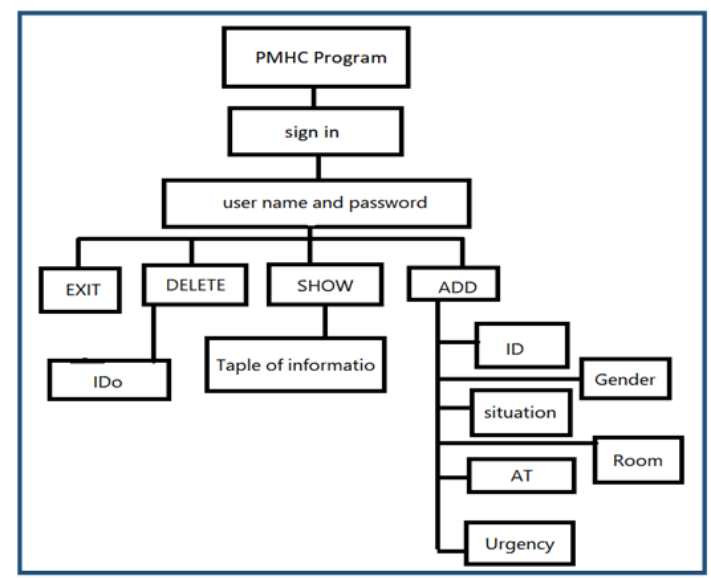

Figure 7: Component Diagram

\section{e) Programming Language}

Python is a dynamic, high level, free open source and interpreted programming language. It supports object-oriented programming as well as procedural oriented programming. It has many features made the researchers choose it to implement the system. One of them is that it is free and open source, and also, it is portable language, which helps users to run programs designed on any platform. The researchers took advantage of these features in implementing the system. [7]

\section{f) System Requirements}

The system requires a computer with RAM $256 \mathrm{MB}, 1$ $\mathrm{GHz}$ processor, $40 \mathrm{~GB}$ hard disk as minimum. And windows or Mac operating system to work efficiently.

\section{SYSTEM TESTING}

a) Features to be tested

1. Log in: which allow user accessing the system

2. Register: Adding a new user

3. Add: Adding a new patient profile

4. Show: show patient information

5. Delete: delete patient record

6. Logout: $\log$ out of the system

b) Test Cases

Table 2: Valid log in test case

\begin{tabular}{|c|c|}
\hline \multicolumn{2}{|c|}{ Test Case \#1 } \\
\hline Test Case & Valid log in \\
\hline Test Prionity (Low Medium High) & High \\
\hline Test Title & Verify login process \\
\hline Description & Test user log in with a valid usemame and password \\
\hline
\end{tabular}

ISSN (online): 2581-3048

Volume 4, Issue 6, pp 52-59, June-2020 https://doi.org/10.47001/IRJIET/2020.406007

\begin{tabular}{|c|c|c|c|c|c|}
\hline \multicolumn{6}{|c|}{ Pre-conditions: User has a valid usemame and password } \\
\hline Dependencies: & Test Steps & Test Data & $\begin{array}{c}\text { Expected } \\
\text { Result }\end{array}$ & $\begin{array}{c}\text { Actual } \\
\text { Result }\end{array}$ & $\begin{array}{c}\text { Status } \\
\text { (Pass Fail) }\end{array}$ \\
\hline 1 & Pteps & Asaiyl & $\begin{array}{c}\text { The user is } \\
\text { authorized to } \\
\text { login }\end{array}$ & & \\
\hline 2 & Provide valid password & 1234 & login & $\begin{array}{c}\text { The user is } \\
\text { narigated to } \\
\text { profile in } \\
\text { progam }\end{array}$ & Pass \\
\hline \multicolumn{2}{|l|}{ Result: The username and password have been validated, and the account is logged in } \\
\hline
\end{tabular}

Table 3: Invalid login test case

\begin{tabular}{|c|c|c|c|c|c|}
\hline \multicolumn{6}{|c|}{ Test Case $\# 2$} \\
\hline \multicolumn{3}{|c|}{ Test Case } & \multicolumn{3}{|c|}{ Invalid $L$ og in } \\
\hline \multicolumn{3}{|c|}{ Test Priority (Low/Medium/High): } & \multicolumn{3}{|c|}{ High } \\
\hline \multicolumn{3}{|c|}{ Test Title } & \multicolumn{3}{|c|}{ Verify invalid login process } \\
\hline \multicolumn{3}{|c|}{ Description } & \multicolumn{3}{|c|}{ User try to $\log$ in with invalid username or password. } \\
\hline \multicolumn{6}{|c|}{ Pre-conditions: User has invalid or wrong usemame and password } \\
\hline \multicolumn{6}{|c|}{ Dependencies: } \\
\hline Steps & Test Steps & Test Data & $\begin{array}{c}\text { Expected } \\
\text { Result }\end{array}$ & $\begin{array}{l}\text { Actual } \\
\text { Result }\end{array}$ & $\begin{array}{c}\text { Status } \\
\text { (Pass/Fail) }\end{array}$ \\
\hline 1 & $\begin{array}{l}\text { Provide } \\
\text { username }\end{array}$ & $\begin{array}{l}\text { Name }= \\
\text { asayil12 } \\
3\end{array}$ & Reject login & $\begin{array}{l}\text { the message } \\
\text { will be } \\
\text { appeared (The } \\
\text { usemame or } \\
\text { password is } \\
\text { Wrong) }\end{array}$ & Fail \\
\hline 2 & $\begin{array}{l}\text { Provide invalid } \\
\text { password }\end{array}$ & $\begin{array}{l}\text { Password }= \\
5781\end{array}$ & & & \\
\hline
\end{tabular}

Table 4: Register test case

\begin{tabular}{|c|c|c|c|c|c|}
\hline \multicolumn{6}{|c|}{ Test Case $\# 3$} \\
\hline \multicolumn{3}{|c|}{ Test case } & \multicolumn{3}{|c|}{ Register } \\
\hline \multicolumn{3}{|c|}{ Test Priority (Low Medium/High): } & \multicolumn{3}{|c|}{ High } \\
\hline \multicolumn{3}{|c|}{ Test Title } & \multicolumn{3}{|c|}{ New user system registration } \\
\hline \multicolumn{3}{|c|}{ Description } & \multicolumn{3}{|c|}{$\begin{array}{l}\text { Test the ability to add a new } \\
\text { user. }\end{array}$} \\
\hline \multicolumn{6}{|c|}{ Pre-conditions: Provide a valid usemame, password and new user information. } \\
\hline \multicolumn{6}{|c|}{ Dependencies: } \\
\hline Steps & Test Steps & Test Data & $\begin{array}{c}\text { Expected } \\
\text { Result } \\
\end{array}$ & $\begin{array}{l}\text { Actual } \\
\text { Result }\end{array}$ & $\begin{array}{c}\text { Status } \\
\text { (Pass/Fail) }\end{array}$ \\
\hline 1 & $\begin{array}{l}\text { Provide valid } \\
\text { usemame }\end{array}$ & Mohammed & $\begin{array}{l}\text { The user should } \\
\text { be able to } \\
\text { register }\end{array}$ & $\begin{array}{l}\text { The wser is } \\
\text { navigated to } \\
\text { reginter }\end{array}$ & Pass \\
\hline 2 & $\begin{array}{l}\text { Provide valid } \\
\text { password }\end{array}$ & 1234 & & & \\
\hline 3 & $\begin{array}{l}\text { Click on the } \\
\text { button register }\end{array}$ & & & & \\
\hline
\end{tabular}

Table 5: Add test case

\begin{tabular}{|c|c|c|c|c|c|}
\hline \multicolumn{6}{|c|}{ Test Case $\# 4$} \\
\hline \multicolumn{3}{|c|}{ Test Case } & \multicolumn{3}{|c|}{ Add } \\
\hline \multicolumn{3}{|c|}{ Teat Priority (Low/Medium/High) } & \multicolumn{3}{|c|}{ High } \\
\hline \multicolumn{3}{|c|}{ Test Title } & \multicolumn{3}{|c|}{ Adding patient profile } \\
\hline \multicolumn{3}{|c|}{ Description } & \multicolumn{3}{|c|}{ The ability to add patient information in the system } \\
\hline \multicolumn{6}{|c|}{ Pre-conditions: Availability of patient information and health status } \\
\hline \multicolumn{6}{|c|}{ Dependencies: } \\
\hline Steps & Test Steps & Test Data & $\begin{array}{c}\text { Expected } \\
\text { Result }\end{array}$ & $\begin{array}{l}\text { Actual } \\
\text { Result }\end{array}$ & $\begin{array}{c}\text { Status } \\
\text { (Pass Fail) }\end{array}$ \\
\hline 1 & Log into system & $\begin{array}{l}\text { Mohammed } \\
1234\end{array}$ & $\begin{array}{l}\text { Accept log in } \\
\text { information }\end{array}$ & $\begin{array}{c}\text { Successful } \\
\text { login }\end{array}$ & Pass \\
\hline 2 & $\begin{array}{l}\text { Click on the } \\
\text { button add }\end{array}$ & $\begin{array}{l}\text { Id, gender, } \\
\text { room number }\end{array}$ & Add & $\begin{array}{l}\text { The user can add } \\
\text { data }\end{array}$ & Pass \\
\hline
\end{tabular}


ISSN (online): 2581-3048

\section{IRJIET}

\begin{tabular}{|c|c|c|c|c|c|}
\hline \multicolumn{6}{|c|}{ Table 6: Show test case } \\
\hline \multicolumn{3}{|c|}{ Test Case } & \multicolumn{3}{|c|}{ Show } \\
\hline \multicolumn{3}{|c|}{ Test Priority (Low/Medium/High) } & \multicolumn{3}{|c|}{ High } \\
\hline \multicolumn{3}{|c|}{ Test Title } & \multicolumn{3}{|c|}{ Show patients information on monitor. } \\
\hline \multicolumn{3}{|c|}{ Description } & \multicolumn{3}{|c|}{$\begin{array}{l}\text { Test the ability to display patient's information on } \\
\text { monitor. }\end{array}$} \\
\hline \multicolumn{6}{|c|}{ Pre-conditions: Authorized user, and information to be display. } \\
\hline \multicolumn{6}{|c|}{ Dependencies: } \\
\hline Steps & Test Steps & Test Data & $\begin{array}{l}\text { Expected } \\
\text { Result }\end{array}$ & $\begin{array}{l}\text { Actual } \\
\text { Result }\end{array}$ & $\begin{array}{l}\text { Status } \\
\text { (Pass Fail) }\end{array}$ \\
\hline 1 & $\begin{array}{l}\text { Chick on the } \\
\text { button show }\end{array}$ & $\begin{array}{l}\text { Id, gender, healthy } \\
\text { case classification } \\
\text { room...etc. }\end{array}$ & show & $\begin{array}{c}\text { Display } \\
\text { information }\end{array}$ & Pass \\
\hline
\end{tabular}

Table 7: Delete test case

\begin{tabular}{|c|c|c|c|c|c|}
\hline \multicolumn{6}{|c|}{ Test Case $\# 6$} \\
\hline \multicolumn{3}{|c|}{ Test cave } & \multicolumn{3}{|c|}{ Delete } \\
\hline \multicolumn{3}{|c|}{ Test Priority (Low/Medium/High) } & \multicolumn{3}{|c|}{ Med } \\
\hline \multicolumn{3}{|c|}{ Test Title } & \multicolumn{3}{|c|}{ Delete patient's profile } \\
\hline \multicolumn{3}{|c|}{ Description } & \multicolumn{3}{|c|}{$\begin{array}{l}\text { Test the effectiveness of deleting one or more } \\
\text { patients' record. }\end{array}$} \\
\hline \multicolumn{6}{|c|}{ Pre-conditions: Authorized user, and stored patient record. } \\
\hline \multicolumn{6}{|c|}{ Dependencies: } \\
\hline Steps & Test Steps & Test Data & $\begin{array}{l}\text { Expected } \\
\text { Result }\end{array}$ & $\begin{array}{l}\text { Actual } \\
\text { Result }\end{array}$ & $\begin{array}{c}\text { Status } \\
\text { (Pass Fail) }\end{array}$ \\
\hline 1 & $\begin{array}{l}\text { Click on the } \\
\text { display button }\end{array}$ & & & & \\
\hline 2 & $\begin{array}{l}\text { Click on the } \\
\text { Delete button }\end{array}$ & Id1 delete & Delete & Delete id1 & pass \\
\hline
\end{tabular}

Table 8: Log out test case

\begin{tabular}{|c|c|c|c|c|c|}
\hline \multicolumn{6}{|c|}{ Test Case 47} \\
\hline \multicolumn{3}{|c|}{ Test Case } & \multicolumn{3}{|l|}{ Log out } \\
\hline & \multicolumn{2}{|c|}{ Test Priority (Low/Medium/High) } & \multicolumn{3}{|c|}{ High } \\
\hline \multicolumn{3}{|c|}{ Test Title } & \multicolumn{3}{|c|}{ Verify log out of the system } \\
\hline \multicolumn{3}{|c|}{ Description } & \multicolumn{3}{|c|}{ Test the validity of $\log$ out bottom } \\
\hline \multicolumn{6}{|c|}{ Pre-conditions: A logged in uver } \\
\hline \multicolumn{6}{|c|}{ Dependencies: } \\
\hline Steps & Test Steps & Test Data & $\begin{array}{r}\text { Expected } \\
\text { Result }\end{array}$ & $\begin{array}{l}\text { Actual } \\
\text { Result }\end{array}$ & $\begin{array}{r}\text { Status } \\
\text { (Pass/Fail) }\end{array}$ \\
\hline 1 & $\begin{array}{l}\begin{array}{c}\text { Naxigate to } \log \text { out } \\
\text { button }\end{array} \\
\end{array}$ & & & & \\
\hline 4 & $\begin{array}{l}\text { Click on the } \\
\text { Log out button }\end{array}$ & Log out & Log out from system & $\begin{array}{l}\text { Log out from } \\
\text { system }\end{array}$ & Pass \\
\hline \multicolumn{6}{|c|}{ Result: The user logged out successfully. } \\
\hline
\end{tabular}

\section{RESULT AND DISCUSSION}

As a result, a system for the emergency department has been built depending on the Canadian system, which achieves its functionalities as mentioned bellow.

When the system starts, a welcome interface appears as in figure (8), which includes registration and login bottoms to allow user login or register a new account.

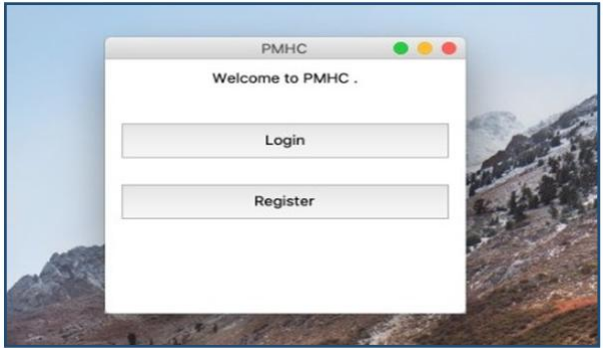

Volume 4, Issue 6, pp 52-59, June-2020 https://doi.org/10.47001/IRJIET/2020.406007

When a user click on $\log$ in bottom, a $\log$ in window appears, only authorized can login.

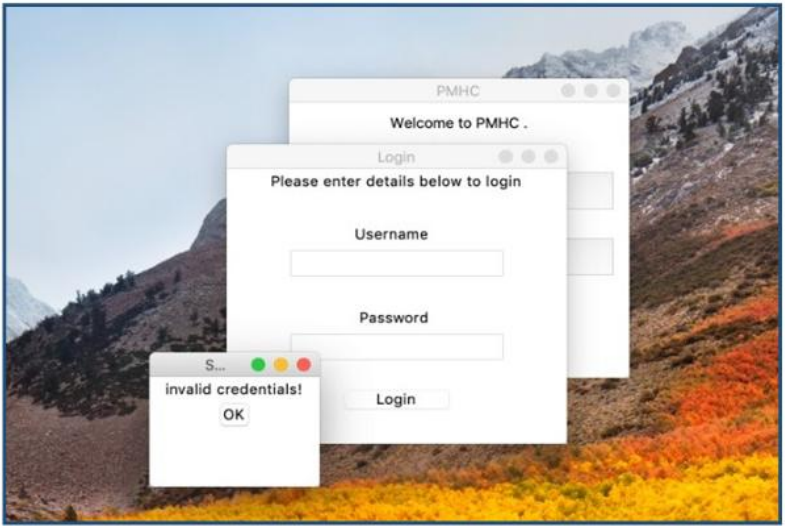

Figure 9: Login process

Figures (10) and (11) show the registration for a new system user.

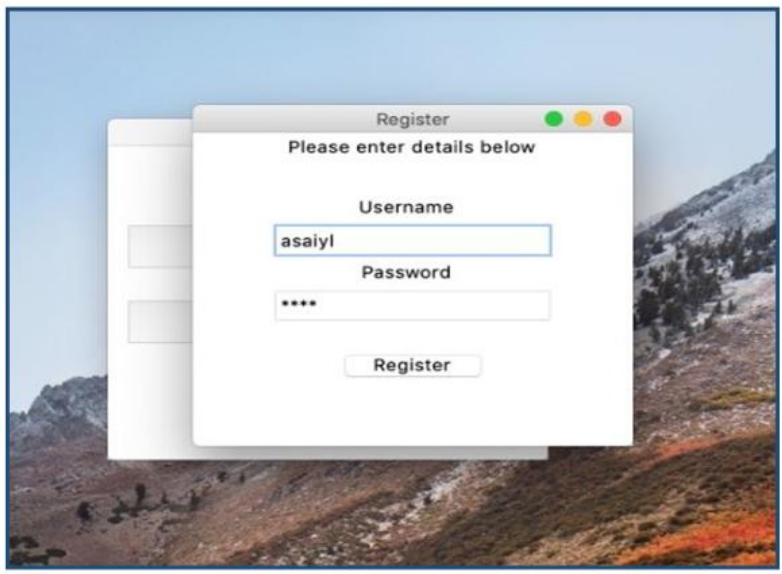

Figure 10: Registration

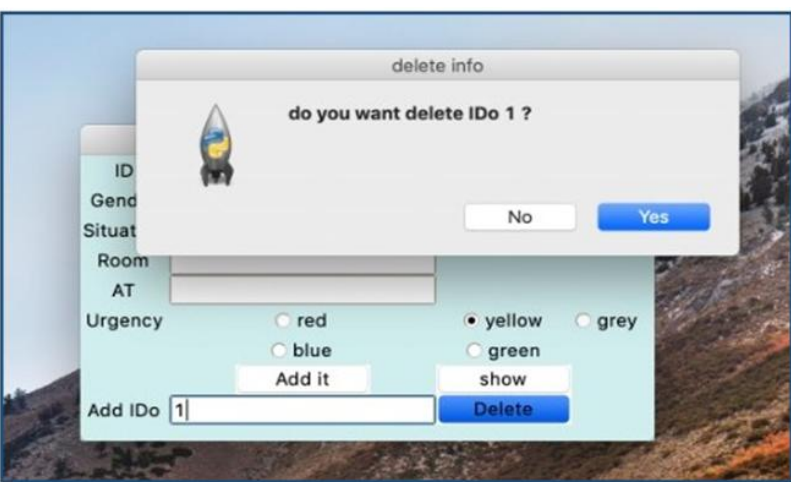

Figure 11: Registration success

Figure (12) shows home page, where authorized user can add a new patient profile, show information, or delete a stored record.

Figure 8: Welcome Interface 


\section{/}

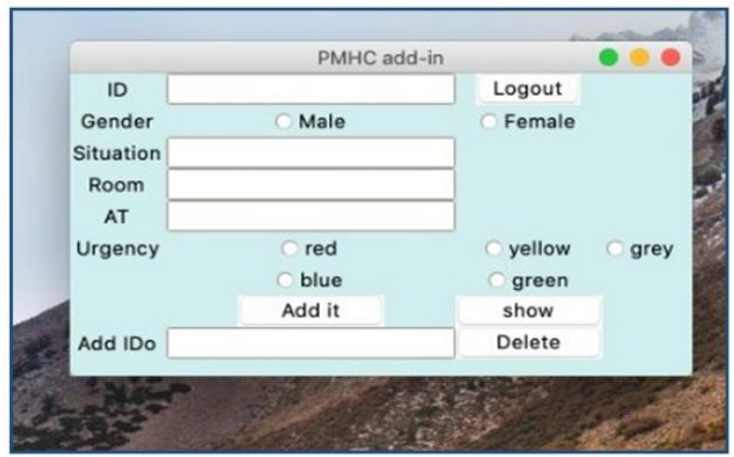

Figure 12: Home page

Figure (13) shows adding a new patient profile steps.

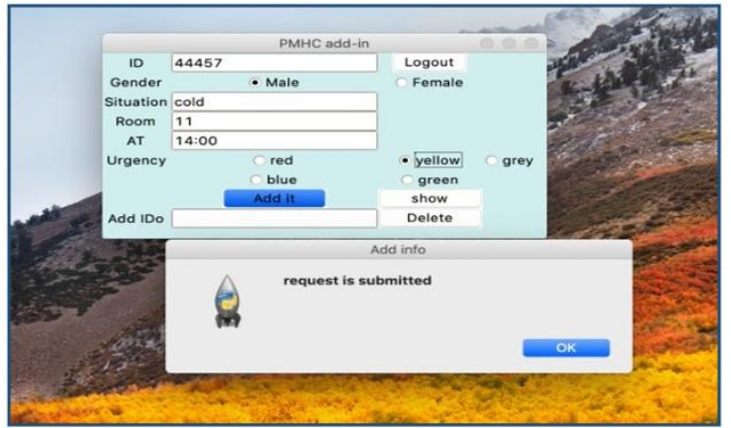

Figure 13: Adding a new patient profile

Figure (14) shows the sorted patients information with different colors, according to the Canadian system and patient arrival time.

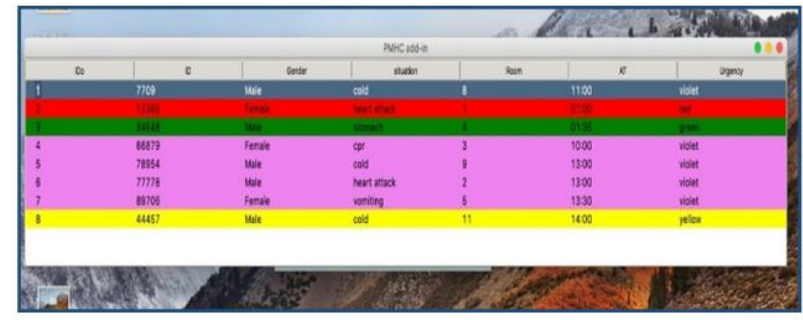

Figure 14: Display monitor

Authorized user can delete a patient record, by his ID number, as shown in figure (15).

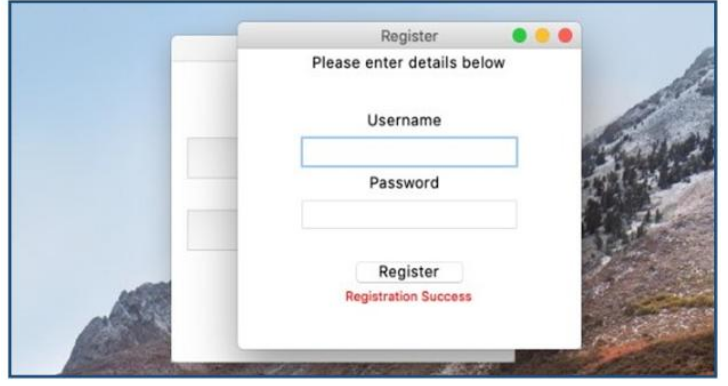

Figure 15: Delete a patient record

ISSN (online): 2581-3048

Volume 4, Issue 6, pp 52-59, June-2020 https://doi.org/10.47001/IRJIET/2020.406007

\section{CONCLUSION}

A queuing model system is built depending on the Canadian system, and implemented using python and SQL programming languages. The system performs number of tasks, include adding a new patient profile, deleting an existing one, and the most important task is showing sorted patients' information in different colors depending on their health situation and arrival time. Also, one of the main functionalities is to have an electronic control panel to observe patient's status from sign in till the leaving decision.

\section{REFERENCES}

[1] Gilboy, Nicki; Tanbue, Paula;, ESI - A Triage Tool for Emergency Department Care, Boston: Harverd Medical School, 2011.

[2] "Emergency Q," [Online]. Available: https://www.emergencyq.com/. [Accessed 2020].

[3] H. \&. C. I. Network, "NHSquicker," [Online]. Available: https://nhsquicker.co.uk/. [Accessed 22 May 2020].

[4] K. A. U. HOSPITAL, "SHIFAA," King Abdulaziz University Hospital - Information Technology, 2017. [Online]. Available: https://shifaa.kau.edu.sa/defaulten.aspx. [Accessed 22 May 2020].

[5] W. KENTON, "Investopedia," Dotdash, 10 Jul 2019. [Online].

Available: https://www.investopedia.com/terms/q/queuingtheory.asp. [Accessed 23 May 2020].

[6] Sommerville Ian, 2011. Software Engineering 9th Ed, Pearson Education Inc, USA.

[7] MKS075, "GreeksforGreeks," [Online]. Available: https://www.geeksforgeeks.org/python-features/. [Accessed 11 June 2020].

\section{AUTHOR'S BIOGRAPHIES}
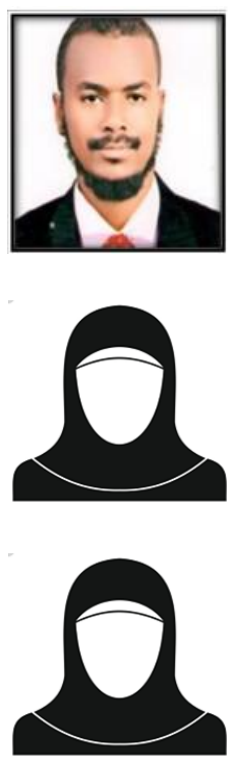

Dr. Mohammed Awad Mohammed Ata Elfadiel, Assistant professor in computer science. Open university of sudan and College of Sharia and Islamic Studies at Al-Ahsa, Imam Muhammad bin Saud Islamic University, Saudi Arabia.

Dr. Eiman Alsiddig Altayeb Ibrahim, Assistant professor, College of computer science and information technology, Omdurman Islamic university, Sudan.

Sara Abdullah Saud Al-Owaidh, Bachelor of Computer Science, Department of Computer Science and Information, College of Sharia and Islamic Studies at Al-Ahsa, Imam Muhammad bin Saud Islamic University, Saudi Arabia. 
ISSN (online): 2581-3048

Haya Khalid Fadhel Al-Aqeel, Bachelor of Computer Science, Department of Computer Science and Information, College of Sharia and Islamic Studies at Al-Ahsa, Imam Muhammad bin Saud Islamic University, Saudi Arabia.

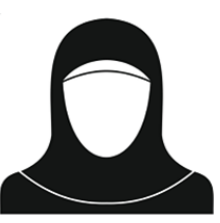

https://doi.org/10.47001/IRJIET/2020.406007

Asaiyl Saud Yahya Al-Oudah, Bachelor of Computer Science, Department of Computer Science and Information, College of Sharia and Islamic Studies at Al-Ahsa, Imam Muhammad bin Saud Islamic University, Saudi Arabia.

\section{Citation of this Article:}

Mohammed Awad Mohammed AtaElfadiel, Eiman Alsiddig Altayeb Ibrahim, Sara Abdullah Saud Al-Owaidh, Haya Khalid Fadhel Al-Aqeel, Asaiyl Saud Yahya Al-Oudah, "Building a System for the Hospital's Emergency Departments Based on the Queuing Theory" Published in International Research Journal of Innovations in Engineering and Technology - IRJIET, Volume 4, Issue 6, pp 52-59, June 2020. https://doi.org/10.47001/IRJIET/2020.406007 